CLINICAL STUDY

\title{
Smoking is negatively associated with the presence of thyroglobulin autoantibody and to a lesser degree with thyroid peroxidase autoantibody in serum: a population study
}

\author{
Inge Bülow Pedersen, Peter Laurberg, Nils Knudsen ${ }^{1}$, Torben Jørgensen ${ }^{2}$, Hans Perrild ${ }^{1}$, Lars Ovesen ${ }^{3}$
} and Lone Banke Rasmussen ${ }^{4}$

Department of Endocrinology and Medicine, Aalborg Hospital, Aarhus University Hospital, DK-9000 Aalborg, Denmark, ${ }^{1}$ Endocrine Unit, Medical Clinic I, Bispebjerg Hospital, DK-2400 Copenhagen, Denmark, ${ }^{2}$ Research Centre for Prevention and Health, Glostrup University Hospital, Glostrup, DK-2600 Denmark, ${ }^{3}$ Department of Gastroenterology, Slagelse Hospital, Slagelse, Denmark and ${ }^{4}$ Department of Nutrition, National Food Institute, DK-1790 Denmark

(Correspondence should be addressed to I B Pedersen; Email: i.bulow@rn.dk)

\begin{abstract}
Background: Autoimmune thyroid diseases are common and the prevalence of circulating thyroid antibodies (thyroid peroxidase antibody, TPO-Ab and thyroglobulin antibody, Tg-Ab) is high in the population. The knowledge of a possible association between lifestyle factors and circulating thyroid antibodies is limited.

Aim: To evaluate the correlation between smoking habits and the presence of circulating TPO-Ab and $\mathrm{Tg}-\mathrm{Ab}$.

Material and methods: In a cross-sectional comparative population study performed in two areas of Denmark with moderate and mild iodine deficiency, 4649 randomly selected subjects from the population in some predefined age groups between 18 and 65 years were examined. Blood tests were analysed for $\mathrm{TPO}-\mathrm{Ab}$ and $\mathrm{Tg}-\mathrm{Ab}$ using assays based on the RIA technique. The participants answered questionnaires, were clinically examined and blood and urine samples collected.

Results: Data were analysed in multivariate logistic regression models. There was a negative association between smoking and the presence of thyroid autoantibodies in serum. This association was observed for the presence of TPO-Ab and/or Tg-Ab, TPO-Ab (without respect to Tg-Ab status), $\mathrm{Tg}-\mathrm{Ab}$ (without respect to TPO-Ab status) and both antibodies together. The association between smoking and thyroid autoantibodies was stronger for $\mathrm{Tg}$-Ab than for TPO-Ab. There was no association between smoking and $\mathrm{TPO}-\mathrm{Ab}$ measured alone or between smoking and TPO-Ab when Tg-Ab was included in the model as an explanatory variable.

Conclusion: Smoking was negatively associated with the presence of thyroid autoantibodies with the strongest association between smoking and $\mathrm{Tg}-\mathrm{Ab}$. The study design precludes any conclusions as to the cause of the negative association between smoking thyroid autoantibodies.
\end{abstract}

European Journal of Endocrinology 158 367-373

\section{Introduction}

Like many other autoimmune diseases, autoimmune thyroiditis is thought to be multifactorial in origin with both genetic and environmental factors playing a role in disease development $(1,2)$.

There is a good correlation between the thyroid autoimmunity evaluated from lymphocytic infiltration in the thyroid and the presence of thyroid autoantibodies in serum $(3,4)$.

Several mechanisms have been suggested for the development of circulating thyroid peroxidase antibody (TPO-Ab) and thyroglobulin antibody (Tg-Ab) (5). Some mechanisms involve more general aberrations of the immune system, while others focus on abnormalities in presentation or structure of individual antigens. We previously described a similar prevalence rate of TPO-Ab and $\mathrm{Tg}-\mathrm{Ab}$ in the population (6) and suggested a common mechanism behind the generation of the two antibodies.

During the last few years, there has been a focus on a more general association between smoking and the immune system, and the incidence and severity of some autoimmune diseases seem to be influenced by tobacco smoking (7). A negative association between smoking and celiac disease and ulcerative colitis has been observed $(8,9)$, whereas an increased incidence of psoriasis and Crohn's disease has been found in smokers when compared with non-smokers $(10,11)$.

Thyroid abnormalities may be associated with smoking (12-16). In iodine-deficient populations, a positive 
association between smoking and multinodular goitre and between smoking and the level of thyroglobulin has been reported $(13,17)$. The positive association between smoking and Graves' hyperthyroidism and Graves' orbitopathy has been described unambiguously (18, 19). Subclinical hypothyroidism seems to occur less commonly in smokers $(13,20)$, whereas results from the studies of overt autoimmune hypothyroidism are inconsistent (19). Smoking has also been reported to be a risk factor for the development of post-partum thyroid dysfunction (21). Knowledge of a possible association between lifestyle factors including smoking and circulating thyroid antibodies (TPO-Ab and Tg-Ab) in the population is limited (22).

The aim of the present study was to evaluate the correlation between smoking habits and the presence of circulating TPO-Ab and Tg-Ab in the population.

\section{Subjects and methods}

\section{Study population}

This study is part of The Danish Investigation of Iodine Intake and Thyroid Diseases (DanThyr), which is the official clinical monitoring of the Danish iodine fortification programme. The present study took place from March 1997 to June 1998 before iodine fortification of salt was implemented in Denmark.

A sample of females within the following age groups, young adults (18-22 years), mid-gestational (25-30 years), premenopausal (40-45 years) and post-menopausal (60-65 years) and males aged 60-65 years living in either Aalborg (Northern Jutland) or Copenhagen, was drawn from the Civil Registration System. The sample contained 40233 subjects who were given random numbers within each group using computer software and invited to the study examination in the order of the given random numbers. The number of subjects invited in each group was adjusted throughout the study period to obtain uniform numbers of participants in each group. Out of 9274 subjects invited, $4649(50.1 \%)$ participated in the examination.

The two sub-cohorts had moderate and mild iodine deficiency respectively reflected by median iodine concentrations in spot urine of $45 \mu \mathrm{g} / \mathrm{l}$ (Aalborg) and $61 \mu \mathrm{g} / \mathrm{l}$ (Copenhagen) when the subjects taking iodine supplements were excluded (53 and $68 \mu \mathrm{g} / \mathrm{l}$ in all the subjects) (23). The cohort has been described in detail previously (24).

Participants previously treated for thyroid disease $(n=224)$, and women who had been pregnant within the past 12 months $(n=141)$ were excluded from this study. The participants with missing measurements (thyroid antibodies, $n=98$; serum thyroid-stimulating hormone (TSH), $n=4$; urinary iodine, $n=45$ or information on smoking habits, $n=6$ or alcohol consumption, $n=6$ ) were also excluded leaving 4125 for the analysis (females aged 18-22 years, $n=884$; $25-30$ years, $n=788 ; 40-45$ years, $n=847 ; 60-65$ years, $n=717$ and males aged $60-65$ years, $n=889$ ).

\section{Data collection}

The participants answered questionnaires concerning previous treatment for thyroid disease and lifestyle factors. They were asked about present or previous smoking, daily or occasional smoking, type of smoking (cigarettes, cheroots, cigars or pipe tobacco), amount of tobacco consumed, years of smoking and years since cessation of smoking. A clinical examination and an interview were conducted by a medical doctor. Blood and urine samples were collected.

\section{Laboratory procedures}

Serum TPO-Ab and Tg-Ab were both measured by RIA (DYNO test anti-TPO and DYNO test anti-Tg; BRAHMS Diagnostica, Berlin, Germany). The assays and evaluation of cut-off values have been described in detail previously (11). The following detection limits were used: $\mathrm{TPO}-\mathrm{Ab}>30 \mathrm{U} / \mathrm{l}$ and $\mathrm{Tg}-\mathrm{Ab}>20 \mathrm{U} / \mathrm{l}$, both corresponding to the functional sensitivity given by the manufacturer.

The iodine content in spot urine was measured in duplicate by Ce/As method after alkaline ashing (25), as described previously (26). The analytical sensitivity of the assay was $2 \mu \mathrm{g} / \mathrm{l}$.

\section{Definition of data and statistical analysis}

Most of the smokers smoked only cigarettes $33.1 \%$ of participants), $1 \%$ were smokers of cheroots, $0.2 \%$ cigars and $2.6 \%$ smoked pipe tobacco. The different types of preferred smoking were combined in the analyses; thus, cigarettes were regarded as containing $1 \mathrm{~g}$ tobacco each, cheroots $3 \mathrm{~g}$ and cigars $5 \mathrm{~g}$. The smoking habit of each participant was classified in two separate ways: 1) daily smoker, occasional smoker or non-smoker and 2) never smoker (never daily use tobacco), ex-smoker (previous daily use of tobacco), moderate smoker (1-19 g/day) or heavy smoker ( $\geq 20 \mathrm{~g} /$ day). The classification of smoking habits was based on questionnaires only. Alcohol consumption was classified in two classes according to the recommendations of the National Board of Health in Denmark (low and moderate alcohol intake (0-14 drinks/week for females and 0-21 drinks/week for males) and high alcohol intake ( $>14$ drinks/week for females and $>21$ drinks/ day for males)).

The data analyses were performed with SPSS software (version 13.0 SPSS software, Inc., Chicago, Illinois, USA). The $\chi^{2}$-test was used to compare the number of subjects in different groups. In some of the analyses, the group of occasional smokers $(n=194)$ was excluded. 
The association between smoking and thyroid autoantibodies (TPO-Ab and $\mathrm{Tg}-\mathrm{Ab}$ ) was analysed in logistic regression models for dichotomous variables. Data were generally analysed in multivariate models allowing adjustment for age and sex group, region of inhabitancy, iodine excretion, alcohol consumption and familial occurrence of thyroid disease.

There was a difference in the frequency of smoking between regions and between the five age and sex groups. Interactions between smoking and region and between smoking and age and sex group were tested in the models to describe a possible difference in the impact of smoking on thyroid autoantibodies between regions and age and sex groups. No significant interaction was found.

The study was approved by the regional Ethics Committees in Northern Jutland and Copenhagen. All the participants gave written informed consent.

\section{Results}

Overall, thyroid autoantibodies (TPO-Ab and/or Tg-Ab) were more common in non-smokers when compared with daily smokers $(21.4 \%$ vs $15.4 \%, P<0.001$; Table 1). The prevalence rate of TPO-Ab and/or Tg-Ab was equal in occasional smokers compared with daily smokers $(15.4 \%$ vs $15.5 \%, P=$ n.s). The distribution of different combinations of $\mathrm{TPO}-\mathrm{Ab}$ and $\mathrm{Tg}-\mathrm{Ab}$ in subgroups of the participants and the prevalence rate of daily smoking are shown in Table 2 .

As a first step, the association between thyroid autoantibodies and smoking was analysed in multivariate logistic regression models with smoking divided into three subclasses: daily, occasional and nonsmokers. There was a negative association between thyroid autoantibodies (TPO-Ab and/or Tg-Ab) and daily smoking (daily smoking versus non-smoking: odds ratio (OR), 0.66 and 95\% confidence intervals (CI), 0.55-0.79). A small and non-significant tendency of a lower risk for TPO-Ab and/or Tg-Ab in occasional smokers when compared with non-smokers was present (OR, 0.82 and CI, 0.54-1.24). As the small group of occasional smokers $(n=194)$ was difficult to classify precisely, it was excluded from the following analyses.

To evaluate the impact of the amount of tobacco smoked, the data were analysed with smoking divided into four subclasses: heavy, moderate, ex- and never smokers (Fig. 1). In both heavy and moderate smokers, the risk for having TPO-Ab and/or Tg-Ab, Tg-Ab (without respect to TPO-Ab) or both antibodies measured together was lower when compared with never smokers. There was no statistical difference in the risk between moderate and heavy smokers (moderate versus heavy, TPO-Ab and/or Tg-Ab, OR (CI), 1.09 (0.81-1.47); TPO-Ab, 1.04 (0.74-1.44); Tg-Ab, 1.26 (0.86-1.86) and both antibodies, 1.23 (0.75-2.02)). Neither were there statistical differences in the risks between ex- and never smokers for having different combinations of thyroid autoantibodies (Fig. 1).

For the next analyses, the definition of smoking was simplified and divided into smoking (heavy and moderate smokers) and non-smoking (ex- and never smokers). The associations between smoking in two classes and different combinations of thyroid antibodies are shown in Fig. 2. There was no association between smoking and TPO-Ab measured alone, but a weak negative association between smoking and TPO-Ab (without respect to $\mathrm{Tg}$-Ab status) was present. The most pronounced association was found between smoking and $\mathrm{Tg}-\mathrm{Ab}$ (without respect to TPO-Ab status) and $\mathrm{Tg}-\mathrm{Ab}$ measured alone.

As expected, there was a clear association between the presence of TPO-Ab and $\mathrm{Tg}-\mathrm{Ab}$ in serum $(P<0.001)$. The inclusion of TPO-Ab as an explanatory variable in the logistic regression model with $\mathrm{Tg}-\mathrm{Ab}$ as dependent variable did not influence the association between smoking and Tg-Ab. When Tg-Ab as explanatory variable was included in the model for TPO-Ab, the weak association between TPO-Ab and smoking disappeared.

Table 1 Prevalence rate (\%) of thyroid peroxidase antibody (TPO-Ab) and thyroglobulin antibody (Tg-Ab) in participants with different smoking habits.

\begin{tabular}{|c|c|c|c|c|c|c|}
\hline Smoking subclasses & $\begin{array}{c}\text { TPO-Ab and/or } \\
\text { Tg-Ab }\end{array}$ & TPO-Ab ${ }^{a}$ & $\mathbf{T g}-\mathbf{A b} \mathbf{b}^{\mathrm{b}}$ & $\begin{array}{l}\text { TPO-Ab and } \\
\text { Tg-Ab }\end{array}$ & TPO-Ab only & Tg-Ab only \\
\hline \multicolumn{7}{|c|}{ 1) Daily smoker, occasional smoker or non-smoker } \\
\hline Daily $(n=1542)$ & 15.4 & 11.7 & 8.6 & 5.0 & 6.7 & 3.6 \\
\hline Occasional $(n=194)$ & 15.5 & 8.2 & 11.9 & 4.6 & 3.6 & 7.2 \\
\hline Non-smoker $(n=2389)$ & 21.4 & 14.4 & 15.9 & 9.0 & 5.5 & 6.9 \\
\hline \multicolumn{7}{|c|}{ 2) Never smoker, ex-smoker, moderate smoker or heavy smoker } \\
\hline Heavy $(n=562)$ & 14.6 & 11.6 & 7.5 & 4.4 & 7.1 & 3.0 \\
\hline Moderate $(n=980)$ & 15.8 & 11.8 & 9.3 & 5.3 & 6.5 & 4.0 \\
\hline Ex-smoker $(n=793)$ & 20.8 & 15.1 & 14.4 & 8.7 & 6.4 & 5.7 \\
\hline Never smoker $(n=1596)$ & 21.7 & 14.1 & 16.7 & 9.1 & 5.0 & 7.6 \\
\hline
\end{tabular}

Prevalence rate in percentage of different combinations of detectable thyroid antibodies according to smoking habits in participants with no previously treated thyroid disease or pregnancy within 12 months. Classification of smoking habits: 1) daily smoker, occasional smoker or non-smoker; 2) never smoker, ex-smoker, moderate smoker or heavy smoker. In 2, occasional smokers have been excluded.

${ }^{a}$ Without respect to $\mathrm{Tg}-\mathrm{Ab}$ status.

bWithout respect to TPO-Ab status. 
Table 2 Prevalence rate (\%) of smoking and thyroid peroxidase antibody (TPO-Ab) and thyroglobulin antibody (Tg-Ab) in the cohort stratified according to age and sex.

\begin{tabular}{|c|c|c|c|c|c|c|c|c|}
\hline $\begin{array}{l}\text { Gender and } \\
\text { age (years) }\end{array}$ & Number & Smoking & $\begin{array}{c}\text { TPO-Ab and/or } \\
\mathrm{Tg}-\mathrm{Ab}\end{array}$ & TPO-Ab ${ }^{a}$ & $\operatorname{Tg}-A b^{b}$ & $\begin{array}{l}\text { TPO-Ab } \\
\text { alone }\end{array}$ & $\begin{array}{l}\text { Tg-Ab } \\
\text { alone }\end{array}$ & $T P O-A b$ and $T g-A b$ \\
\hline Female 18-22 & 806 & 33.7 & 12.0 & 7.3 & 8.8 & 3.2 & 4.7 & 4.1 \\
\hline Female 25-30 & 728 & 38.3 & 19.4 & 12.9 & 14.8 & 4.5 & 6.5 & 8.4 \\
\hline Female $40-45$ & 823 & 47.5 & 24.9 & 19.3 & 15.6 & 9.4 & 5.6 & 10.0 \\
\hline Female $60-65$ & 709 & 33.7 & 29.5 & 21.6 & 19.9 & 9.6 & 7.9 & 12.0 \\
\hline Male 60-65 & 865 & 41.8 & 11.1 & 7.1 & 7.5 & 3.6 & 4.0 & 3.5 \\
\hline Total & 3931 & 39.3 & 19.0 & 13.4 & 13.1 & 6.0 & 5.6 & 7.4 \\
\hline
\end{tabular}

Prevalence rate in percentage of smoking and detectable thyroid antibodies in the participants with no previously treated thyroid disease or pregnancy within 12thinsp;months. Occasional smokers and cases with missing blood or urine test results have been excluded. Prevalence rate in percentage of different combinations of detectable thyroid antibodies according to smoking habits in participants with no previously treated thyroid disease or pregnancy within 12 months. Classification of smoking habits: 1) daily smoker, occasional smoker or non-smoker and 2) never smoker, ex-smoker, moderate smoker or heavy smoker. In 2, occasional smokers have been excluded.

Without respect to $\mathrm{Tg}-\mathrm{Ab}$ status.

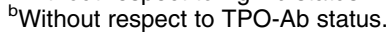

Finally, we studied whether the negative association between smoking and the presence of thyroid autoantibodies depended on the level of serum TSH. As illustrated in Fig. 3, thyroid antibodies were much more common when TSH was elevated, but no difference in the effect of smoking was apparent. This was confirmed in logistic regression models.

\section{Discussion}

In this random sample of 4125 subjects from the population, we found a significant negative association between smoking and the presence of thyroid autoantibodies. The association was most pronounced for $\mathrm{Tg}-\mathrm{Ab}$ and was independent of TPO-Ab. There was only a weak association between smoking and TPO-Ab, and one might question whether that association was due to the higher prevalence of $\mathrm{Tg}-\mathrm{Ab}$ in $\mathrm{TPO}-\mathrm{Ab}$-positive than TPO-Ab-negative subjects.

It is difficult to compare results from different epidemiological studies on thyroid abnormalities as different biochemical and epidemiological methods have been applied. This includes differences in the sensitivity and cut-off values of the assays and whether the study has been population-based or patient-based. The Third National Health and Nutrition Examination Survey (NHANES III) study is the only study prior to the present looking at the possible association between smoking and the prevalence of circulating autoantibodies in the population (20). In the NHANES III study, TPO-Ab and $\mathrm{Tg}-\mathrm{Ab}$ were measured in 15592 subjects representative of the US population. In accordance with the present study, there was a lower proportion of smokers with $\mathrm{TPO}-\mathrm{Ab}$ and/or Tg-Ab compared with non-smokers when adjusted for possible confounders. The association persisted between smoking and TPO-Ab (independent of

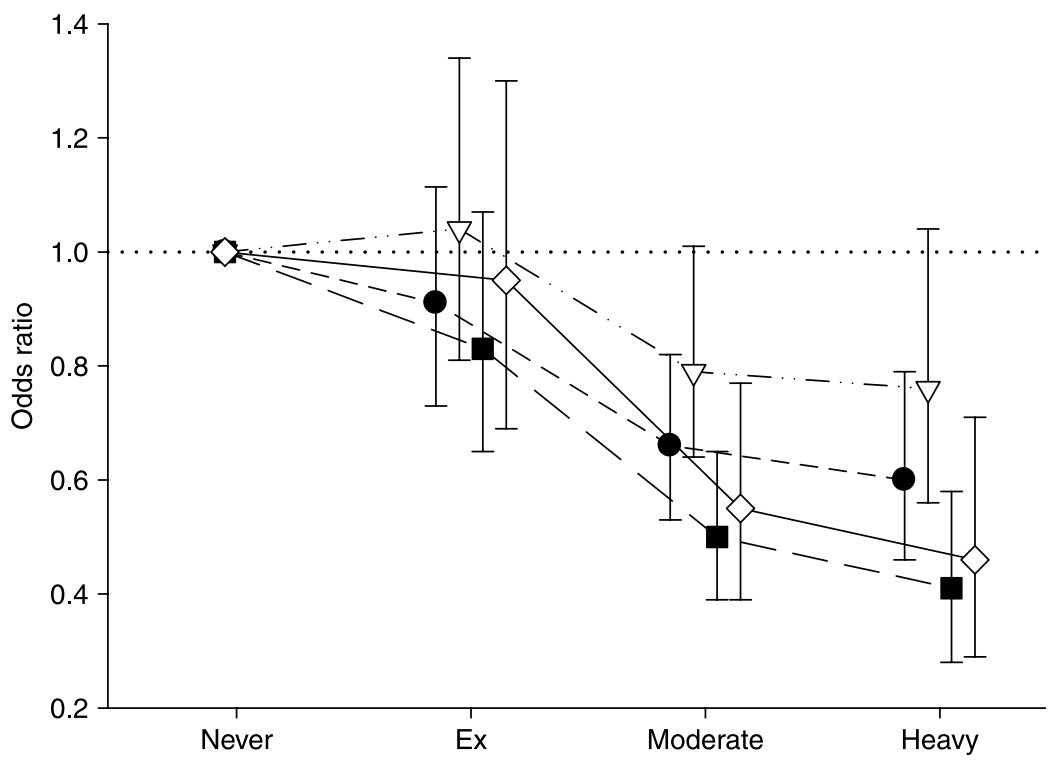

Figure 1 The association between tobacco smoking and the presence of thyroid autoantibodies (TPO-Ab and/or Tg-Ab (०), TPO-Ab $(\nabla)$, Tg-Ab $(\boldsymbol{\square})$ and TPO-Ab and $\operatorname{Tg}-\mathrm{Ab}(\diamond))$ in 3931 randomly selected subjects from the Danish population with no previous thyroid disease and pregnancy within 1 year. Occasional smokers have been excluded. Data were analysed in multivariate logistic regression models adjusting for age and sex group, region of inhabitancy, iodine excretion, alcohol consumption and familial occurrence of thyroid disease. Vertical bars represent $95 \%$ confidence intervals $(\mathrm{Cl})$. odds ratio values are significantly different from the reference (never smoking) when the $\mathrm{Cl}$ does not include 1 . 


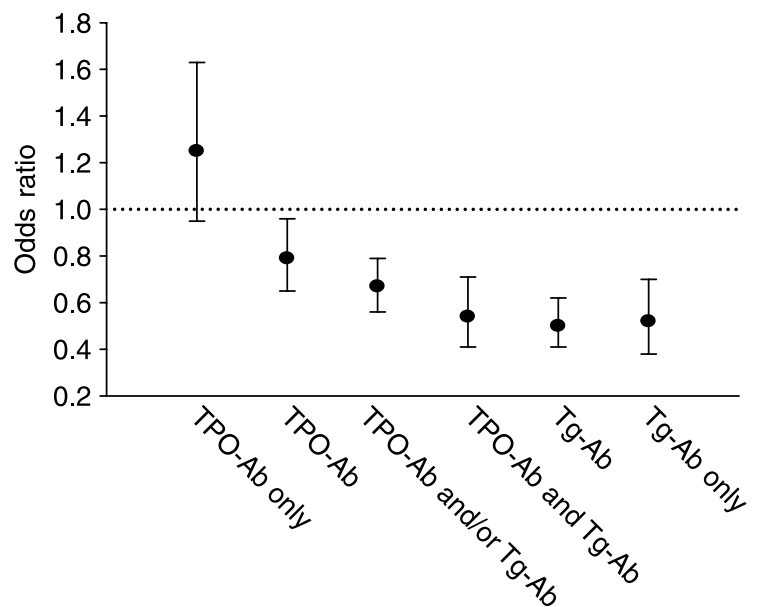

Figure 2 The association between tobacco smoking and presence of different combinations of thyroid antibodies in 3931 randomly selected Danes with no previous treated thyroid disease or pregnancy within 1 year prior to the study. Occasional smokers have been excluded. Data were analysed in multivariate regression models. Vertical bars represent $95 \% \mathrm{Cl}$ for the OR. There was a negative association between thyroid antibodies and smoking with the strongest association when $\mathrm{Tg}-\mathrm{Ab}$ was present.

$\mathrm{Tg}-\mathrm{Ab}$ status) and $\mathrm{Tg}-\mathrm{Ab}$ (independent of $\mathrm{TPO}-\mathrm{Ab}$ status). The association between smoking and TPO-Ab or $\mathrm{Tg}-\mathrm{Ab}$ present alone was not described. In a study by Strieder et al. (27) including 803 first- or second-degree female relatives of patients with documented autoimmune thyroid disease, there was a higher proportion of non-smokers than smokers in the group of participants with positive TPO-Ab. No information on $\mathrm{Tg}-\mathrm{Ab}$ was given. Goh et al. found significantly lower levels of $\mathrm{TPO}-\mathrm{Ab}$ in smokers compared with non-smokers with eye complications due to debuting GD (28). No information on $\mathrm{Tg}-\mathrm{Ab}$ was given.

The major cause for spontaneous overt hypothyroidism is an autoimmune destruction of the thyroid gland (29). Nearly all patients with newly diagnosed overt hypothyroidism are TPO-Ab- and/or Tg-Ab-positive

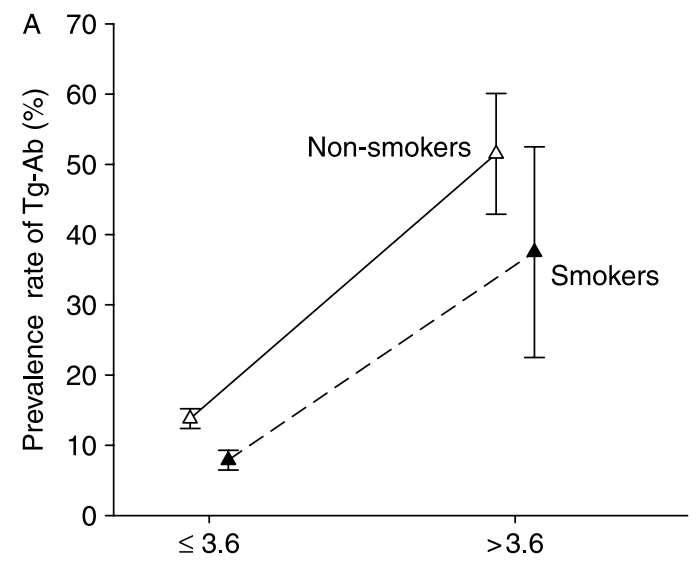

TSH (mIU/l)

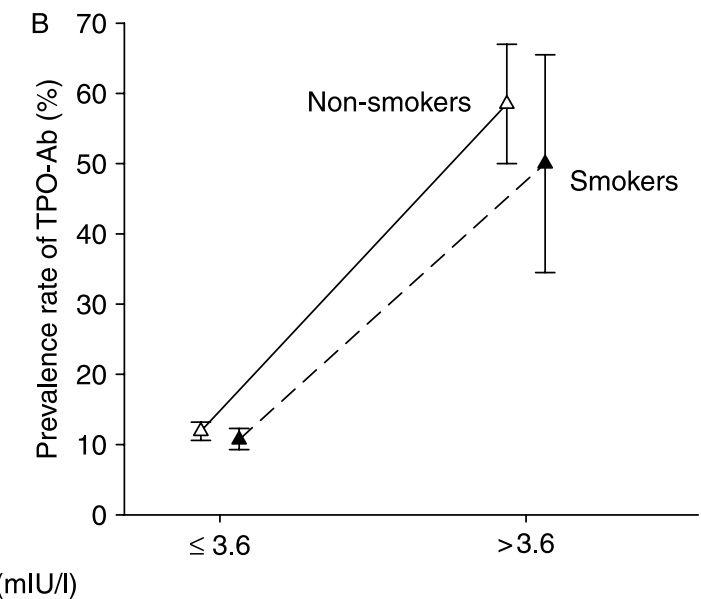

Figure 3 Prevalence rate in percentage of Tg-Ab (A) and TPO-Ab (B) in smokers $(\mathbf{\Delta})$ and non-smokers $(\Delta)$ with different levels of TSH. 
compared with TPO-Ab. It could be speculated that the lower prevalence rate of subclinical hypothyroidism and thereby a lower stimulation of the thyroid gland might reduce thyroid autoimmunity. This phenomenon has also been suggested as a possible explanation for the reduced risk of thyroid cancer in smokers (38). However, we found no evidence that the effect of smoking depended on serum TSH. Other possibilities are direct effects of smoke on the immune system via among others the nicotinic anti-inflammatory pathway (7), via increased cortisol release (39) or a direct interference with iodide transport and organification. Finally, it cannot be excluded that the reduced risk of thyroid autoantibodies in smokers could be caused by an unknown lifestyle factor associated with smoking rather than smoking itself.

In conclusion, we found that smoking was negatively associated with the presence of thyroid autoantibodies with the strongest association between smoking and $\mathrm{Tg}-\mathrm{Ab}$. The study design precludes any conclusions as to the cause of the negative association between smoking and development of thyroid autoantibodies.

\section{Acknowledgements}

This study was a part of The Danish Investigation of Iodine Intake and Thyroid Diseases (DanThyr), which is supported by grants from the Danish Medical Foundation, the 1991 Pharmacy Foundation, North Jutland County Research Foundation, Tømmerhandler Wilhelm Bangs Foundation and Copenhagen Hospital Corporation Research Foundation.

\section{References}

1 Marcocci $\mathrm{C} \&$ Chiovato L. Thyroid-directed antibodies. In The Thyroid, edn 8, pp 414-431. Eds LE Braverman \& RD Utiger, Philadelphia: Lippincott, 2000.

2 Davidson A \& Diamond B. Autoimmune diseases. New England Journal of Medicine 2001345 340-350.

3 Abreau CM, Vagenakis AG, Roti E \& Braverman LE. Clinical evaluation of hemagglutination method for microsomal and thyroglobulin antibody in autoimmune thyroid disease. Annals of Clinical and Laboratory Science 19797 73-78.

4 Kasagi K, Kousaka T, Higuchi K, Lida Y, Misaki T, Alam MS, Miyamoto S, Yamabe $\mathrm{H} \&$ Konishi J. Clinical significance of measurements of antithyroid antibodies in the diagnosis of Hashimoto's thyroiditis: comparison with histological findings. Thyroid $19966445-450$.

5 Weetman AP \& McGregor AM. Autoimmunity thyroid disease: further developments in our understanding. Endocrine Reviews $199415788-830$.

6 Pedersen IB, Laurberg P, Knudsen N, Jørgensen T, Perrild H, Ovesen L \& Rasmussen LB. A population study of the association between thyroid autoantibodies in serum and abnormalities in thyroid function and structure. Clinical Endocrinology 200562 713-720.
7 Scott DA \& Martin M. Exploitation of the nicotinic antiinflammatory pathway for the treatment of epithelial inflammatory diseases. World Journal of Gastroenterology 200612 7451-7459.

8 Thomas GA, Rhodes J \& Ingram JR. Mechanisms of disease: nicotine - a review of its actions in the context of gastrointestinal disease. Nature Clinical Practice. Gastroenterology and Hepatology 20052 536-544.

9 Snook JA, Dwyer L, Lee-Elliott C, Khan S, Wheeler DW \& Nicholas DS. Adult coeliac disease and cigarette smoking. Gut $19963960-62$.

10 Fortes C, Mastroeni S, Leffondre K, Sampogna F, Melchi F, Mazzotti E, Pasquini P \& Abeni D. Relationship between smoking and the clinical severity of psoriasis. Archives of Dermatology 2005 141 1580-1584.

11 Johnson GJ, Cosnes J \& Mansfield JC. Review article: smoking cessation as primary therapy to modify the course of Crohn's disease. Alimentary Pharmacology and Therapeutics $2005 \mathbf{2 1}$ 921-931.

12 Bartelana L, Bogazzi F, Tanda ML, Manetti L, Dell’Unto E \& Martino E. Cigarette smoking and the thyroid. European Journal of Endocrinology $1995133507-512$.

13 Knudsen N, Bülow I, Laurberg P, Ovesen L, Perrild H \& Jørgensen T. High occurrence of thyroid multinodularity and low occurrence of subclinical hypothyroidism among tobacco smokers in a large population study. Journal of Endocrinology 2002 175 571-576.

14 Knudsen N, Bülow I, Laurberg P, Ovesen L, Perrild H \& Jørgensen T. Association of tobacco smoking with goiter in a low-iodine-intake area. Archives of Internal Medicine 2002162 439-443.

15 Pontikides $\mathrm{N}$ \& Krassas GE. Influence of cigarette smoking on thyroid function, goiter formation and autoimmune thyroid disorders. Hormones 20021 91-98.

16 Hegedus L, Karstrup S, Veiergang D, Jacobsen B, Skovsted L \& Feldt-Rasmussen U. High frequency of goitre in cigarette smokers. Clinical Endocrinology 198522 287-292.

17 Christensen SB, Ericsson UB, Janzon L, Tibblin S \& Melander A. Influence of cigarette smoking on goiter formation, thyroglobulin, and thyroid hormone levels in women. Journal of Endocrinology and Metabolism 198458 615-618.

18 Bartelana L, Marcocci C, Tanda ML, Manetti L, Dell'Unto E, Bartolomei MP, Nardi M, Martino E \& Pinchera A. Cigarette smoking and treatment outcomes in Graves ophtalmopathy. Annals of Internal Medicine $1998129632-635$.

19 Vestergaard P. Smoking and thyroid disorders - a meta-analysis. European Journal of Endocrinology 2002146 153-161.

20 Belin RM, Astor BC, Powe NR \& Ladenson PW. Smoke exposure is associated with a lower prevalence of serum thyroid autoantibodies and thyrotropin concentration elevation and a higher prevalence of mild thyrotropin concentration suppression in the Third National Health and Nutrition Examination Survey (NHANES III). Journal of Endocrinology and Metabolism 200489 6077-6086.

21 Kuijpens JL, Pop VJ, Vader HL, Drexhage HA \& Wiersinga WM. Prediction of post partum thyroid dysfunction: can it be improved? European Journal of Endocrinology 1998139 36-43.

22 Weetman AP. Autoimmune thyroid disease: propagation and progression. European Journal of Endocrinology $2003 \mathbf{1 4 8} 1-9$.

23 Rasmussen LB, Ovesen L, Bülow I, Jørgensen T, Knudsen N, Laurberg $\mathrm{P} \&$ Perrild H. Dietary iodine intake and urinary iodine excretion in a Danish population: effect of geography, supplements and food choice. British Journal of Nutrition 2002 87 61-69.

24 Knudsen N, Bülow I, Jørgensen T, Laurberg P, Ovesen L \& Perrild H. Goitre prevalence and thyroid dysfunction in a population with borderline iodine deficiency. Clinical Endocrinology 199953 479-485.

25 Wilson B \& Van Zyl A. The estimation of iodine in thyroidal amino acids by alkaline ashing. South African Journal of Medical Sciences $19673070-82$. 
26 Laurberg P. Thyroxine and 3,5,3'-triiodothyronine content of thyroglobulin in thyroid needle aspirates in hyperthyroidism and hypothyroidism. Journal of Clinical Endocrinology and Metabolism $198764969-974$.

27 Strieder TGA, Prummel MF, Tijssen JGP, Endert E \& Wiersinga WM. Risk factors for and prevalence of thyroid disorders in a crosssectional study among healthy female relatives of patients with autoimmune thyroid disease. Clinical Endocrinology 200359 396-401.

28 Goh SY, Ho SC, Seah LL, Fong KS \& Khoo DHC. Thyroid autoantibody profiles in ofhthalmic dominant and thyroid dominant Graves' disease differ and suggest ophthalmopathy is a multiantigenic disease. Clinical Endocrinology 200460 600-607.

29 Livolsi V. The pathology of autoimmune thyroid disease: a review. Thyroid $19944333-339$.

30 Carlé A, Laurberg P, Knudsen N, Perrild H, Ovesen L, Rasmussen LB, Jørgensen T \& Bülow Pedersen I. Thyroid peroxidase and thyroglobulin auto-antibodies in patients with newly diagnosed overt hypothyroidism. Autoimmunity 200639 497-503.

31 Feldt-Rasmussen U, Hoier-Madsen M, Bech K, Blichert-Toft M, Bliddal H, Date J, Danneskiold-Samsoe B, Hegedus L, Hippe E \& Hornnes PJ. Anti-thyroid peroxidase antibodies in thyroid disorders and non-thyroid autoimmune diseases. Autoimmunity 19919 245-254.

32 Nordyke RA, Gilbert FI Jr, Miyamoto LA \& Fleury KA. The superiority of antimicrosomal over antithyroglobulin antibodies for detection Hashimoto's thyroiditis. Journal of Endocrinological Investigation $19939862-865$.

33 Fukayama H, Nasu M, Murakami S \& Sugawara M. Examination of antithyroid effects of smoking products in cultured thyroid follicles: only thiocyanate is a potent antithyroid agent. Acta Endocrinologica 1992127 520-525.
34 Knudsen N, Bülow I, Jørgensen T, Laurberg P, Ovesen L \& Perrild H. Comparative study of thyroid function and types of thyroid dysfunction in two areas in Denmark with slightly different iodine status. European Journal of Endocrinology $2000143485-491$.

35 Laurberg P, Pedersen KM, Hreidarsson A, Sigfusson N, Iversen E \& Knudsen P. Iodine intake and the pattern of thyroid disorders: a comparative epidemiological study of thyroid abnormalities in the elderly in Iceland and in Jutland, Denmark. Journal of Clinical Endocrinology and Metabolism 199883 765-769.

36 Hintze G, Burghardt U, Baumert J, Windeler J \& Köbberling J. Prevalence of thyroid dysfunction in elderly subjects from the general population in an iodine deficiency area. Aging 19913 325-331.

37 Pedersen IB, Knudsen N, Jørgensen T, Perrild H, Ovesen L \& Laurberg P. Thyroid peroxidase and thyroglobulin autoantibodies in a large survey of populations with mild and moderate iodine deficiency. Clinical Endocrinology 200358 36-42.

38 Mack WJ, Preston-Martin S, Maso LD, Galanti R, Xiang M, Franceschi S, Hallquist A, Jin F, Kolonel L, La Vecchia C, Levi F, Kinos A, Lund E, McTiernan A, Mabuchi K, Negri E, Wingren G \& Ron E. A pooled analysis of case-control studies of thyroid cancer: cigarette smoking and consumption of alcohol, coffee, and tea. Cancer Causes and Control 200314 773-785.

39 Badrick E, Kirschbaum C \& Kumari M. The relationship between smoking status and cortisol secretion. Journal of Clinical Endocrinology and Metabolism 200792 819-824.

Received 8 November 2007

Accepted 3 December 2007 